\section{Hyperpyrexia following hemispherotomy and role of unconventional therapy}

\section{Priyanka Korepu, Kamath Sriganesh, Byrappa Vinay}

Non-infectious fever following surgery occurs in children undergoing hemispherectomies and leads to diagnostic dilemma. ${ }^{[1]}$ Early recognition and treatment is vital to avoid unscrupulous use of antibiotics. This central fever is resistant to routinely used antipyretics while cerebro-spinal fluid (CSF) release with an external ventricular drain (EVD) has shown benefit. ${ }^{[2]}$

A 6-year-old girl, weighing $30 \mathrm{~kg}$ presented with left-sided limb weakness and difficulty in walking. Her parents gave 4-year history of seizures refractory to medical management. She was treated with oxcarbazepine $600 \mathrm{mg} / \mathrm{d}$ and sodium-valproate $450 \mathrm{mg} / \mathrm{d}$. Electroencephalogram (EEG) demonstrated background epileptiform slow-wave discharges with phase-reversal on right fronto-temporal hemisphere. Magnetic resonance imaging (MRI) showed atrophy of right hemisphere, ipsilateral lateral ventricle dilatation and signal changes in subcortical white-matter. A diagnosis of Rasmussen encephalitis was made based on European consensus criteria. ${ }^{[3]}$ Sodium-valproate dose was increased to $450 \mathrm{mg} / \mathrm{d}$ and methylprednisolone $500 \mathrm{mg} / \mathrm{d}$ was administered for 5 days, following which she was able to walk with support. As seizure persisted, clonazepam and leviteracitam were added. Video-EEG showed seizures arising from right hemisphere. Right functional hemispherotomy lasting 8 hours was performed to control intractable seizures under standard anaesthetic management. She received $300 \mathrm{ml}$ of packed red cells. EVD was placed at the end of surgery and elective ventilation instituted for 16 hours. At extubation, tracheal secretions were mucoid and leucocyte count was 11500 cells $/ \mathrm{mm}^{3}$. One hundred and fifty millilitres of clear CSF was drained over 24-hour period. Eighteen hours after surgery, patient had a temperature spike of $106^{\circ} \mathrm{F}$ with heart rate of 180 beats / minute and respiratory rate of 26 breaths/minute. Intravenous paracetamol $15 \mathrm{mg} / \mathrm{kg}$ administered twice over 6-hours period, nimesulide $75 \mathrm{mg}$, cold intravenous fluids and frequent tepid sponging reduced fever but failed to restore normothermia. Urine, CSF and sputum examinations were negative for infective aetiology. Intramuscular chlorpromazine $25 \mathrm{mg}$ was added and other anti-fever measures were continued. Following this, temperature normalised, about 20 hours after manifestation [Figure 1]. Rest of the hospital stay was uneventful.

Post-neurosurgical hyperpyrexia is not uncommon and could be due to both infective and non-infective causes. Blood transfusion, vascular injury, intracranial haemorrhage, operative site infection, meningitis, drugs or extensive tissue damage are common causes for new-onset post-neurosurgical fever. ${ }^{[4]}$ Severe hyperpyrexia $\left(106^{\circ} \mathrm{F}\right)$ as observed in this patient is generally not seen. Most fever of non-infectious aetiology subsides on its own or is unresponsive to conventional anti-pyretics. However, fever in patients with seizure need to be aggressively managed to prevent adverse outcomes. Kossoff et al. ${ }^{[4]}$ reported fever in $82 \%$ of hemidecortication surgeries of which only $5.8 \%$ were infective in origin. Rest they claim were due to aseptic meningitis. Conventional anti-pyretics act by inhibiting cyclooxygenase enzyme and reduce prostaglandin $\mathrm{E}_{2}$ levels within hypothalamus. Despite draining the CSF, hyperpyrexia occurred in our patient necessitating exploration of alternative therapies. When traditional management failed, chlorpromazine achieved fever control. Chlorpromazine produces antipyretic action because of its ability to render patient thermolabile and its effect on thermoregulation. ${ }^{[5]}$

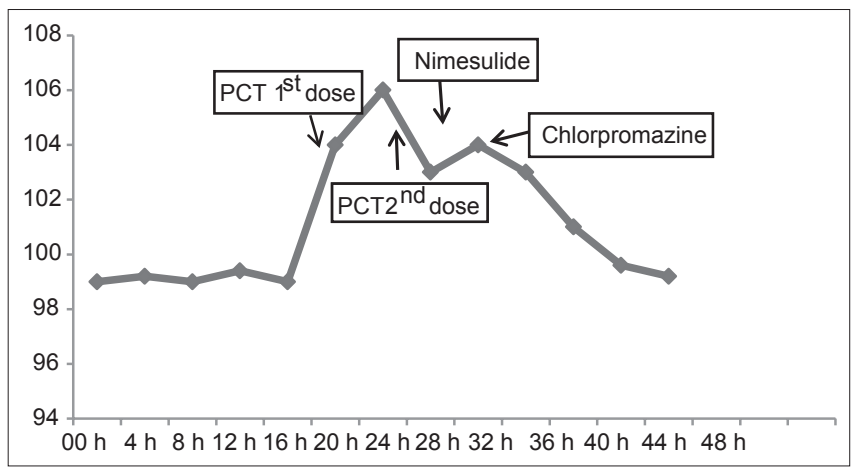

Figure 1: Temperature trend over the $1^{\text {st }} 48 \mathrm{~h}$ of surgery

Department of Neuroanaesthesia, National Institute of Mental Health and Neurosciences, Bangalore, Karnataka, India

Address for correspondence:

Dr. Kamath Sriganesh, Department of Neuroanaesthesia, National Institute of Mental Health and Neurosciences, Bangalore - 560029 , Karnataka, India. E-mail: drsri23@rediffmail.com 
To conclude, defective thermoregulation occurs after hemispherotomy. Conventional anti-pyretics may be ineffective in controlling fever. Chlorpromazine may have contributed to reduced severity and duration of hyperthermia along with other measures and can be considered early in such scenarios.

\section{REFERENCES}

1. de Almeida AN, Marino $\mathrm{R}$ Jr. The early years of hemispherectomy. Pediatr Neurosurg 2005;41:137-40.

2. Sood S, Asano E, Chugani HT. Role of external ventriculostomy in the management of fever after hemispherectomy. J Neurosurg Pediatr 2008;2:427-9.

3. Bien CG, Granata T, Antozzi C, Cross, JH, Dulac O, Kurthen M, et al. Pathogenesis, diagnosis and treatment of Rasmussen encephalitis: A European consensus statement. Brain 2005; 128:454-71.

4. Kossoff EH, Vining EP, Pyzik PL, Kriegler S, Min KS, Carson BS, et al. The postoperative course and management of 106 hemidecortications. Pediatr Neurosurg 2002;37:298-303.

5. Shemano I, Nickerson M. Effect of ambient temperature on thermal response to drugs. Can J Biochem Physiol 1958;36:1243-9.

\begin{tabular}{|l|l|}
\hline \multicolumn{2}{|c|}{ Access this article online } \\
\hline Quick Response Code: & Website: \\
\hline & www.jnaccjournal.org \\
\cline { 2 - 2 } & \\
\hline
\end{tabular}

